\title{
From Cisplatin-Containing Sequential Radiochemotherapy towards Concurrent Treatment for Patients with Inoperable Locoregional Non-Small Cell Lung Cancer: Still Unanswered Questions
}

\author{
C. C. E. Koning, ${ }^{1}$ J. S. A. Belderbos, ${ }^{2}$ and A. L. J. Uitterhoeve ${ }^{1}$ \\ ${ }^{1}$ Department of Radiation Oncology, Academic Medical Center (AMC), University of Amsterdam, P.O. Box 22660, \\ 1100 DD Amsterdam, The Netherlands \\ ${ }^{2}$ Department of Radiation Oncology, Netherlands Cancer Institute/Antoni Van Leeuwenhoek Hospital, P.O. Box 90203, \\ 1006 BE Amsterdam, The Netherlands
}

Correspondence should be addressed to C. C. E. Koning, c.c.koning@amc.uva.nl

Received 10 August 2010; Revised 18 November 2010; Accepted 25 November 2010

Academic Editor: Vito Lorusso

Copyright (c) 2010 C. C. E. Koning et al. This is an open access article distributed under the Creative Commons Attribution License, which permits unrestricted use, distribution, and reproduction in any medium, provided the original work is properly cited.

Radiotherapy has been the mainstay of the treatment of stage III non-small cell lung cancer (NSCLC) patients. In the early nineties, combined treatment with chemotherapy was introduced. In 1995, a meta-analysis showed improved treatment outcome of the sequential use of radiochemotherapy (RCT) compared to radiotherapy alone, provided cisplatin was part of the chemotherapy course. Concurrent RCT compared to radiotherapy only yielded the same improvements of $4 \%$ in the 2 -year and $2 \%$ in the 5 -year overall survival rates. Just recently, two meta-analyses demonstrated that concurrent RCT is definitely superior to sequential RCT in terms of local control and 2-, 3-, and 5-year survival. However, several unanswered questions remain concerning the optimal chemotherapy regimen and radiotherapy doses and techniques in terms of treatment outcome and toxicity profile. Arguments supporting a daily low-dose cisplatin scheme are presented because of comparable radiosensitizing characteristics and favourable side effects. Increasing radiotherapy doses applied according to up-to-date techniques and combinations with new biologicals might lead to further treatment improvements.

\section{Introduction}

Until the nineties radiotherapy alone was the standard treatment for stages IIIA and IIIB non-small cell lung cancer (NSCLC). With the standard dose of 60 Gy in 30 fractions, results in terms of 1-, 2-, and 5-year survival rates were poor [1]. For NSCLC a dose-effect relationship exists: the higher the radiation dose, the greater the probability of tumour control [2]. Kong et al. reported improved local control and survival for patients irradiated with doses above $74 \mathrm{~Gy}$ in the dose escalation trial of the University of Michigan. Strategies to improve the treatment results include increasing doses of radiotherapy and decreasing overall treatment time [3]. A different option is to combine radiotherapy with chemotherapy. The first report on improved 1- and 2-year survival after adding chemotherapy to the irradiation was published by Dillman et al. in 1990 [4].

\section{Sequential Radiochemotherapy}

The strategy of radiotherapy only changed essentially after the publication of the meta-analysis by the Non-small Cell Lung Cancer Collaborative Group in 1995 [5].

Radiotherapy preceded by (usually) two courses of chemotherapy yielded an improvement of the 2-year overall survival rate from $21 \%$ to $25 \%$. The 5 -year survival increased from $6 \%$ to $8 \%$ provided that the chemotherapy regimen included cis-diamminedichloroplatinum II (cisplatin). Without cisplatin no improvements in treatment outcome were achieved. 
The effect was explained by a reduction of distant metastases. Until now this effect of a lower distant metastasis rate was observed in one study only [6]. In this study, Le Chevalier et al. compared radiotherapy alone to chemotherapy and radiotherapy. However, patients with adenocarcinoma were excluded. Since an important proportion of the NSCLC patients were not included, the results might not be representative. The 3 -year survival rate was $12 \%$ for the combination arm versus $4 \%$ for the radiotherapy arm $(P<.02)$. To our knowledge, these results have never been confirmed.

Until recently sequential cisplatin-containing radiochemotherapy has been the standard treatment for inoperable stage IIIA and B disease. Various chemotherapy schedules have been applied, but the treatment outcome did not differ significantly.

\section{Concurrent Radiochemotherapy}

A different approach of combining chemotherapy and radiotherapy was studied in Europe. After phase I and phase II studies, the EORTC started a 3-arm phase III trial comparing split-course radiotherapy of 55 Gy using the same radiotherapy scheme, concurrently combined with $30 \mathrm{mg} / \mathrm{m}^{2}$ cisplatin once a week or $6 \mathrm{mg} / \mathrm{m}^{2}$ daily in 1984 [7-9].

The results were published in 1992 [10]. The most important conclusions were as follows: weekly cisplatin administration did not yield a statistically significant improvement; $6 \mathrm{mg} / \mathrm{m}^{2}$ cisplatin daily added to radiotherapy improved survival; this gain was related to improved local progressionfree survival. There was no effect on the distant metastasis rate, and late toxicity was not increased. These data demonstrated that cisplatin improved the radiotherapy effect by radiosensitization. The most frequently reported acute side effects were nausea and vomiting. In 1992, Trovo et al. also published their randomised phase III study [11]. Three weeks of radiotherapy, to a dose $45 \mathrm{~Gy}$, were compared to the same radiotherapy dose with the addition of $6 \mathrm{mg} / \mathrm{m}^{2}$ cisplatin daily. No positive effect on survival was found, however, maybe due to the low radiation dose prescribed.

After the introduction of the newly developed antiemetics, the 5-HT3 antagonists, several other groups reported their results with concurrent radiochemotherapy in NSCLC. Repeatedly two full-dose chemotherapy courses in a variety of cisplatin, doublets or triplets were combined with radiotherapy.

All phase III trials were included in a meta-analysis by Aupérin et al, indicating a $4 \%$ survival gain at 2 years and $2 \%$ at 5 years, for concurrent chemoradiation versus radiotherapy alone, a comparable improvement as observed with the sequential combination [12]. A Cochrane metaanalysis confirmed these conclusions [13]. The concomitantly applied chemotherapy is considered to have radiosensitizing capacities.

In the meantime EORTC study 08844 was followed by phase I-II studies in which the radiotherapy was intensified to reach an accelerated fractionation scheme (66 Gy in 24 fractions) in a reduced overall treatment time (32 days) $[14,15]$. This radiobiologically equivalent dose of at least $78.5 \mathrm{~Gy} / 2 \mathrm{~Gy}(\mathrm{BED} \alpha / \beta=2)$ with daily low-dose cisplatin before each fraction during the entire course was feasible and safe [16].

\section{Sequential versus Concurrent Radiochemotherapy}

Several groups addressed the question of which type of radiochemotherapy to prefer: the sequential or the concurrent combination. In several trials improved 1- and 2-year overall survival rates in favour of the concurrent arm were reported [17-23].

Most of these trials were included in a new metaanalysis based on individual patient data by Aupérin et al, who concluded that concurrent radiochemotherapy yielded superior results compared to the sequential combinations: 2, 3-, and 5-year survival rates of $35.6 \%, 23.8 \%$, and $15.1 \%$ versus $30.3 \%, 18.1 \%$, and $10.6 \%$, respectively $(P=.004)$ [24]. This improved survival was accomplished because of an improved locoregional control. There were no significant differences between the regimens: single or double high-dose chemotherapy or daily low-dose cisplatin. No differences in distant metastasis rate were observed between the two approaches. Within a few months a meta-analysis was published by O'Rourke et al. reporting a 10\% absolute survival benefit at two years [25]. The most important acute but manageable side effect was esophagitis grade 3 to 4 in $18 \%$ of the patients treated with concurrent radiochemotherapy versus $4 \%$ in the patients treated with sequential RCT.

The conclusion was finalized: concurrent radiochemotherapy became the new standard treatment for locally advanced nonmetastasized stages of NSCLC. It should be realized that the trial data were collected in a period before routine staging with FDG-PET and MRI of the brain. In the future improved selection of the patients will contribute to the treatment results.

\section{Unanswered Questions}

New questions arise, however: what is the optimal combination of chemotherapy used concurrently with highdose radiotherapy? To answer this question we took a closer look at the toxicities of the trials included in the meta-analysis of Aupérin et al. [24]. Arbitrarily we selected those studies that included at least 50 patients in the concurrent arm to assemble more reliable data. In the Furuse trial $80 \mathrm{mg} / \mathrm{m}^{2}$ cisplatin was given on days 1 and 29 , combined with vindesine $3 \mathrm{mg} / \mathrm{m}^{2}$ on days $1,8,29$, and 36 and mitomycin $8 \mathrm{mg} / \mathrm{m}^{2}$ on days 1 and 29 with $56 \mathrm{~Gy}$, $2 \mathrm{~Gy} /$ fraction, split-course radiotherapy [20]. In the French trial cisplatin was prescribed during weeks 1 and 5 using a daily dose of $20 \mathrm{mg} / \mathrm{m}^{2}$ together with $50 \mathrm{mg} / \mathrm{m}^{2}$ etoposide. The radiotherapy dose was $66 \mathrm{~Gy}$ in 33 fractions in 6.5 weeks, followed by two consolidation cycles consisting of cisplatin and vinorelbine [19]. The EORTC trial prescribed $6 \mathrm{mg} / \mathrm{m}^{2}$ cisplatin daily combined with $2.75 \mathrm{~Gy}$ radiotherapy, total dose 66 Gy/24 fractions, 5 fractions a week [23].

The study of Zatloukal et al., missing in the metaanalysis, prescribed $80 \mathrm{mg} / \mathrm{m}^{2}$ cisplatin on day 1 and vinorelbine $25 \mathrm{mg} / \mathrm{m}^{2}$ on days 1,8 , and 15 , repeated every 28 
TABLE 1: Survival data and toxicities of concurrent treatment regimens with $\geq 50$ patients included.

\begin{tabular}{lcccc}
\hline Author of publication & Zatloukal et al. [22] & Fournel et al. [19] & Furuse et al. [20] & Belderbos et al. [23] \\
\hline $\begin{array}{l}\text { Number of patients } \\
\text { Survival data (\%) }\end{array}$ & 102 & 205 & 314 & 158 \\
Overall survival 2 years & 34.2 & 26.5 & 34.6 & 34 \\
Overall survival 3 years & 18.6 & 18.6 & 22.3 & 29.2 \\
Acute toxicity (\%) & & & & \\
Neutropenia grade 3+4 & 65 & 77 & 100 & 2 \\
Thrombocytopenia & 6 & 16 & 53 & 0 \\
Anaemia & 12 & 20 & 10 & 0 \\
Esophagitis & 18 & 32 & 3 & 6 \\
Nausea/vomiting & 39 & 24 & 22 & 17 \\
\hline
\end{tabular}

days. The radiotherapy, $60 \mathrm{~Gy} / 30$ fractions during 6 weeks, was started on day 4 resulting in a weekend rest between the chemotherapy administration and start of radiotherapy [22]. The treatment results in terms of 2- and 3-year overall survival are plotted in Table 1 and seem comparable to the daily low-dose cisplatin outcome. For the RTOG study no full paper has been published, and important data on toxicity are lacking [18].

The treatment-related toxicities are listed in Table 1 as well. In general high-dose cisplatin was accompanied by more frequent haematological toxicity. Esophagitis was 3\% in the split-course radiotherapy scheme and more or less equal $(18 \%)$ for the other varieties with exception for the study by Fournel et al. Nausea and vomiting was much lower for the daily low-dose cisplatin combination. Other toxicities such as neuropathy, renal toxicity, and pneumonitis were reported in different ways and were generally infrequent if presented. Fournel reported a striking toxic death rate of $11 \%$, maybe also related to the combination with consolidation chemotherapy treatment. Many patients were not capable to receive the two additional courses after finishing the concurrent radiochemotherapy.

The mild toxicity profile of daily $6 \mathrm{mg} / \mathrm{m}^{2}$ cisplatin and competitive clinical outcome with accelerated radiotherapy compared to full-dose concurrent RCT supports the use of this scheme, although randomized prospective clinical trials will finally yield the proof. To our knowledge until now no such studies have been performed.

In the study of Belderbos et al. the radiation dose was the highest compared to the schemes used in the other reports [23].

Trials studying the role of induction or consolidation chemotherapy show disappointing results $[26,27]$.

\section{Other Arguments in Favour of Daily Low-Dose Cisplatin}

Since the incidence of NSCLC is high among elderly patients (at least $40 \%$ of the patients are older than 70 years in The Netherlands) and many of them have a smoking history, the majority has severe comorbidities. Epidemiological studies show that, with increasing age, the percentage of people treated with chemotherapy decreases. However, age is not an independent prognostic factor in stage III and IV NSCLC [28-30]. Elderly patients with marginal renal function (creatinine clearance $<70 \mathrm{~mL} / \mathrm{min}$ ) or marginal cardiac function (hyperhydration contra-indicated) are eligible for administration of daily low-dose cisplatin, while administration of full-dose chemotherapy is often contraindicated. Combination of concurrent daily cisplatin with radiation appears to be a good alternative, especially in these elderly, frail patients $[31,32]$.

For patients with head and neck tumours, hearing loss due to cisplatin administration was studied and reported low in case of daily low-dose cisplatin compared to highdose courses [33]. Preclinical studies on RCT support the use of daily administration for optimal radiosensitizing effects [34]. However, when logistics make this daily administration too complicated, a weekly cisplatin dose can be considered $\left(40 \mathrm{mg} / \mathrm{m}^{2}\right)$ to conform with the guidelines for radiochemotherapy in patients with cervical cancer [35].

Alternative platinum compounds such as carboplatin have not yielded the same positive results as cisplatin $[36,37]$.

To our opinion the favourable toxicity profile makes the daily low-dose cisplatin with high-dose accelerated radiotherapy combination suitable for addition of new antitumour agents. Many new biologicals have entered the therapeutic domain, several were combined with concurrent RCT regimens. Some combinations appear to be too toxic like the vascular epithelial growth factor antibody bevacizumab [38] or ineffective as the tyrosine kinase inhibitor (TKI) gefitinib [39]. The feasibility of adding the epidermal growth factor receptor inhibitor cetuximab has been recently reported for NSCLC patients [40]. Results of a running randomized phase II trial comparing daily cisplatin with or without cetuximab need to be awaited. Studies on the antifolate pemetrexed are under way [41]. Until now no definite data can be reported.

Other topics for future research are RCT with more sophisticated radiotherapy techniques allowing possibly higher tumour doses and/or lower toxicities in surrounding healthy tissues. For patients with larger tumor volumes, the possibilities to increase the radiation dose were limited by normal tissue constraints (esophagus and spinal cord). 
Intensity-modulated radiotherapy (IMRT) has the potential benefit to further increase the dose that can be safely prescribed in lung cancer patients due to a better conformity index and a steeper dose falloff [42-44]. This technique has been widely introduced recently.

\section{Conclusions}

In conclusion after two decades of mainly sequentially combined treatment, concurrent radiochemotherapy is nowadays the standard treatment. Since the daily low-dose cisplatin can be safely combined with high-dose accelerated radiotherapy, this treatment option is still very appealing. In general oncologists should offer the least harmful treatment to their patients in case several treatment options are available with equal efficacy.

This approach, delivered in a short overall treatment time, is suitable for the elderly and for patients with comorbidities as well. It also offers the opportunity to combine this concomitant radiochemotherapy with new agents.

\section{References}

[1] C. A. Perez, K. Stanley, G. Grundy et al., "Impact of irradiation technique and tumor extent in tumor control and survival of patients with unresectable non-oat cell carcinoma of the lung: report by the Radiation Therapy Oncology Group," Cancer, vol. 50, no. 6, pp. 1091-1099, 1982.

[2] F. M. Kong, R. K. Ten Haken, M. J. Schipper et al., "High-dose radiation improved local tumor control and overall survival in patients with inoperable/unresectable non-small-cell lung cancer: long-term results of a radiation dose escalation study," International Journal of Radiation Oncology Biology Physics, vol. 63, no. 2, pp. 324-333, 2005.

[3] M. I. Saunders and S. Dische, "Continuous, hyperfractionated, accelerated radiotherapy (CHART) in non-small cell carcinoma of the bronchus," International Journal of Radiation Oncology Biology Physics, vol. 19, no. 5, pp. 1211-1215, 1990.

[4] R. O. Dillman, S. L. Seagren, K. J. Propert et al., "A randomized trial of induction chemotherapy plus high-dose radiation versus radiation alone in stage III non-small-cell lung cancer," New England Journal of Medicine, vol. 323, no. 14, pp. 940-945, 1990.

[5] Collaborative Group, "Chemotherapy in non-small cell lung cancer: a meta-analysis using updated data on individual patients from 52 randomised clinical trials," British Medical Journal, vol. 311, no. 7010, pp. 899-909, 1995.

[6] T. Le Chevalier, R. Arriagada, E. Quoix et al., "Radiotherapy alone versus combined chemotherapy and radiotherapy in nonresectable non-small-cell lung cancer: first analysis of a randomized trial in 353 patients," Journal of the National Cancer Institute, vol. 83, no. 6, pp. 417-423, 1991.

[7] H. Jan Keizer, A. B. M. F. Karim, K. Hian Njo et al., "Feasibility study on daily administration of cisdiam-minedichloroplatinum(II) in combination with radiotherapy," Radiotherapy and Oncology, vol. 1, no. 3, pp. 227-234, 1984.

[8] C. Schaake-Koning, H. Bartelink, and B. Hora Adema, "Radiotherapy and cis-diammine dichloroplatinum (II) as a combined treatment modality for inoperable non-small cell lung cancer: a dose finding study," International Journal of Radiation Oncology Biology Physics, vol. 12, no. 3, pp. 379-383, 1986.
[9] C. Schaake-Koning, B. Maat, P. Van Houtte et al., "Radiotherapy combined with low-dose cis-diammine dichloroplatinum (II) (CDDP) in inoperable nonmetastatic non-small cell lung cancer (NSCLC): a randomized three arm phase II study of the EORTC Lung Cancer and Radiotherapy Cooperative Groups," International Journal of Radiation Oncology Biology Physics, vol. 19, no. 4, pp. 967-972, 1990.

[10] C. Schaake-Koning, W. Van den Bogaert, O. Dalesio et al., "Effects of concomitant cisplatin and radiotherapy on inoperable non-small- cell lung cancer," New England Journal of Medicine, vol. 326, no. 8, pp. 524-530, 1992.

[11] M. G. Trovo, E. Minatel, G. Franchin et al., "Radiotherapy versus radiotherapy enhanced by cisplatin in stage III nonsmall cell lung cancer," International Journal of Radiation Oncology Biology Physics, vol. 24, no. 7, pp. 11-15, 1992.

[12] A. Aupérin, C. Le Péchoux, J. P. Pignon et al., "Concomitant radio-chemotherapy based on platin compounds in patients with locally advanced non-small cell lung cancer (NSCLC): a meta-analysis of individual data from 1764 patients," Annals of Oncology, vol. 17, no. 3, pp. 473-483, 2006.

[13] N. P. Rowell and N. P. O'rourke, "Concurrent chemoradiotherapy in non-small cell lung cancer," Cochrane Database of Systematic Reviews, no. 4, Article ID CD002140, 2004.

[14] A. L. J. Schuster-Uitterhoeve, P. J. M. Van De Vaart, C. C. E. Schaake-Koning et al., "Feasibility of escalating daily doses of cisplatin in combination with accelerated radiotherapy in non-small cell lung cancer," European Journal of Cancer A, vol. 32, no. 8, pp. 1314-1319, 1996.

[15] A. L. J. Schuster-Uitterhoeve, M. C. C. M. Hulshof, D. Gonzalez Gonzalez, M. Koolen, and P. Sminia, "Feasibility of curative radiotherapy with a concomitant boost technique in 33 patients with non-small cell lung cancer (NSCLC)," Radiotherapy and Oncology, vol. 28, no. 3, pp. 247-251, 1993.

[16] A. L. J. Uitterhoeve, J. S. A. Belderbos, M. G. J. Koolen et al., "Toxicity of high-dose radiotherapy combined with daily cisplatin in non-small cell lung cancerresults of the EORTC 08912 phase I/II study," European Journal of Cancer, vol. 36, no. 5, pp. 592-600, 2000.

[17] G. Clamon, J. Herndon, W. Eaton et al., "A feasibility study of extended chemotherapy for locally advanced non-small cell lung cancer: a phase II trial of cancer and leukemia group B," Cancer Investigation, vol. 12, no. 3, pp. 273-282, 1994.

[18] W. J. Curran, C. B. Scott, and C. J. Langer, "Long-term benefit is observed in a phase III comparison of sequential versus concurrent chemo-radiation for patients with unresected stage III NSCLC: RTOG 9410," Proceedings of the American Society of Clinical Oncology, vol. 22, p. 621, 2003, abstract no. 2499.

[19] P. Fournel, G. Robinet, P. Thomas et al., "Randomized phase III trial of sequential chemoradiotherapy compared with concurrent chemoradiotherapy in locally advanced non-small-cell lung cancer: groupe Lyon-Saint-Etienne d'Oncologie Thoracique-Groupe Français de PneumoCancérologie NPC 95-01 Study," Journal of Clinical Oncology, vol. 23, no. 25, pp. 5910-5917, 2005.

[20] K. Furuse, M. Fukuoka, M. Kawahara et al., "Phase III study of concurrent versus sequential thoracic radiotherapy in combination with mitomycin, vindesine, and cisplatin in unresectable stage III non-small-cell lung cancer," Journal of Clinical Oncology, vol. 17, no. 9, pp. 2692-2699, 1999.

[21] H. C. Ulutin, M. Güden, K. Oysul, S. Sürenkök, and Y. Pak, "Split-course radiotherapy with or without concurrent or sequential chemotherapy in non-small cell lung cancer," Radiation Medicine, vol. 18, no. 2, pp. 93-96, 2000. 
[22] P. Zatloukal, L. Petruzelka, M. Zemanova et al., "Concurrent versus sequential chemoradiotherapy with cisplatin and vinorelbine in locally advanced non-small cell lung cancer: a randomized study," Lung Cancer, vol. 46, no. 1, pp. 87-98, 2004.

[23] J. Belderbos, L. Uitterhoeve, N. van Zandwijk et al., "Randomised trial of sequential versus concurrent chemoradiotherapy in patients with inoperable non-small cell lung cancer (EORTC 08972-22973)," European Journal of Cancer, vol. 43, no. 1, pp. 114-121, 2007.

[24] A. Aupérin, C. Le Péchoux, E. Rolland et al., "Meta-analysis of concomitant versus sequential radiochemotherapy in locally advanced non-small-cell lung cancer," Journal of Clinical Oncology, vol. 28, no. 13, pp. 2181-2190, 2010.

[25] N. O’Rourke, M. Roqué I Figuls, N. Farré Bernadó, and F. Macbeth, "Concurrent chemoradiotherapy in non-small cell lung cancer," Cochrane Database of Systematic Reviews, vol. 6, Article ID CD002140, 2010.

[26] B. Jeremic and C. Koning, "Induction chemotherapy before chemoradiation in locally advanced non-small-cell lung cancer: failure after failure, again and again," Journal of Clinical Oncology, vol. 26, no. 10, pp. e1-e2, 2008.

[27] E. E. Vokes, "Optimal therapy for unresectable stage III non-small-cell lung cancer," Journal of Clinical Oncology, vol. 23, no. 25, pp. 5853-5855, 2005.

[28] M. L. G. Janssen-Heijnen, S. Smulders, V. E. P. P. Lemmens, F. W. J. M. Smeenk, H. J. A. A. Van Geffen, and J. W. W. Coebergh, "Effect of comorbidity on the treatment and prognosis of elderly patients with non-small cell lung cancer," Thorax, vol. 59, no. 7, pp. 602-607, 2004.

[29] T. Pignon, A. Gregor, C. Schaake Koning, A. Roussel, M. Van Glabbeke, and P. Scalliet, "Age has no impact on acute and late toxicity of curative thoracic radiotherapy," Radiotherapy and Oncology, vol. 46, no. 3, pp. 239-248, 1998.

[30] M. A. Socinski, "Clinical issues in the management of non-small-cell lung cancer and the role of platinum-based therapy," Clinical Lung Cancer, vol. 5, no. 5, pp. 274-289, 2004.

[31] I. Takata, H. Ueoka, K. Kiura et al., "Daily low-dose cisplatin and concurrent thoracic irradiation for poor-risk patients with unresectable non-small-cell lung cancer," Acta Medica Okayama, vol. 56, no. 5, pp. 261-266, 2002.

[32] A. L. J. Uitterhoeve, M. G. J. Koolen, R. M. van Os et al., "Accelerated high-dose radiotherapy alone or combined with either concomitant or sequential chemotherapy; treatments of choice in patients with Non-Small Cell Lung Cancer," Radiation Oncology, vol. 2, no. 1, Article ID 27, 2007.

[33] C. L. Zuur, Y. J. W. Simis, R. S. Verkaik et al., "Hearing loss due to concurrent daily low-dose cisplatin chemoradiation for locally advanced head and neck cancer," Radiotherapy and Oncology, vol. 89, no. 1, pp. 38-43, 2008.

[34] H. Bartelink, R. F. Kallman, D. Rapacchietta, and G. A. M. Hart, "Therapeutic enhancement in mice by clinically relevant dose and fractionation schedules of cis-diamminedichloroplatinum(II) and irradiation," Radiotherapy and Oncology, vol. 6, no. 1, pp. 61-74, 1986.

[35] P. G. Rose, B. N. Bundy, E. B. Watkins et al., "Concurrent cisplatin-based radiotherapy and chemotherapy for locally advanced cervical cancer," New England Journal of Medicine, vol. 340, no. 15, pp. 1144-1153, 1999.

[36] D. Ball, J. Bishop, J. Smith et al., "A randomised phase III study of accelerated or standard fraction radiotherapy with or without concurrent carboplatin in inoperable non-small cell lung cancer: final report of an Australian multi-centre trial," Radiotherapy and Oncology, vol. 52, no. 2, pp. 129-136, 1999.
[37] H. J. M. Groen, A. H. W. van der Leest, E. Fokkema et al., "Continuously infused carboplatin used as radiosensitizer in locally unresectable non-small-cell lung cancer: a multicenter phase III study," Annals of Oncology, vol. 15, no. 3, pp. 427-432, 2004.

[38] D. R. Spigel, J. D. Hainsworth, D. A. Yardley et al., "Tracheoesophageal fistula formation in patients with lung cancer treated with chemoradiation and bevacizumab," Journal of Clinical Oncology, vol. 28, no. 1, pp. 43-48, 2010.

[39] K. Kelly, K. Chansky, L. E. Gaspar et al., "Phase III trial of maintenance gefitinib or placebo after concurrent chemoradiotherapy and docetaxel consolidation in inoperable stage III non-small-cell lung cancer: SWOG S0023," Journal of Clinical Oncology, vol. 26, no. 15, pp. 2450-2456, 2008.

[40] E. E. Schaake, T. S. Aukema, J. Belderbos et al., "Cetuximab in combination with concurrent chemoradiotherapy in locally advanced non-small cell lung carcinoma: a feasibility study," European Journal of Clinical and Medical Oncology. In press.

[41] A. Brade, A. Bezjak, R. MacRae et al., "A phase II study of concurrent pemetrexed/cisplatin/radiation (RT) for unresectable stage IIIA/b non-small cell lung cancer (NSLC)," Journal of Clinical Oncology, vol. 28, article S15, 2010.

[42] I. S. Grills, D. Yan, A. A. Martinez, F. A. Vicini, J. W. Wong, and L. L. Kestin, "Potential for reduced toxicity and dose escalation in the treatment of inoperable non-small-cell lung cancer: a comparison of intensity-modulated radiation therapy (IMRT), 3D conformal radiation, and elective nodal irradiation," International Journal of Radiation Oncology Biology Physics, vol. 57, no. 3, pp. 875-890, 2003.

[43] H. Murshed, H. H. Liu, Z. Liao et al., "Dose and volume reduction for normal lung using intensity-modulated radiotherapy for advanced-stage non-small-cell lung cancer," International Journal of Radiation Oncology Biology Physics, vol. 58, no. 4, pp. 1258-1267, 2004.

[44] M. Schwarz, M. Alber, J. V. Lebesque, B. J. Mijnheer, and E. M. F. Damen, "Dose heterogeneity in the target volume and intensity-modulated radiotherapy to escalate the dose in the treatment of non-small-cell lung cancer," International Journal of Radiation Oncology Biology Physics, vol. 62, no. 2, pp. 561-570, 2005. 


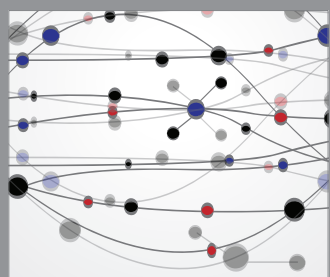

The Scientific World Journal
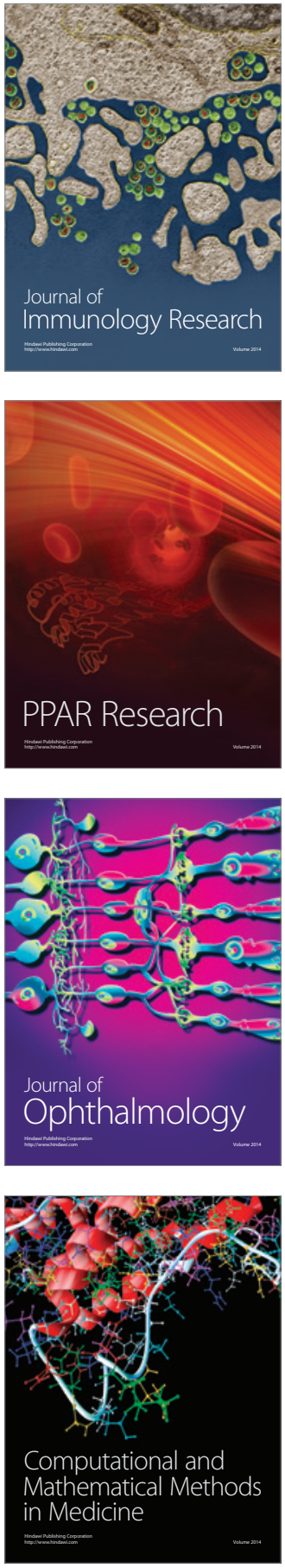

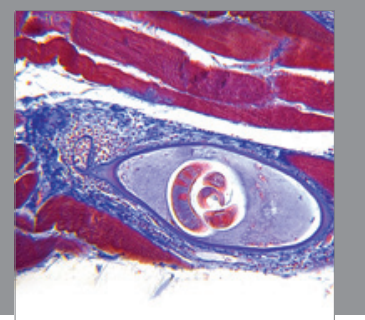

Gastroenterology

Research and Practice
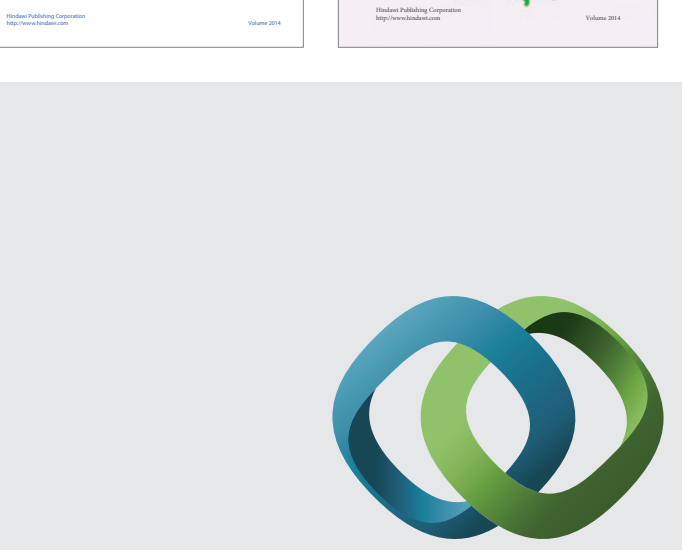

\section{Hindawi}

Submit your manuscripts at

http://www.hindawi.com
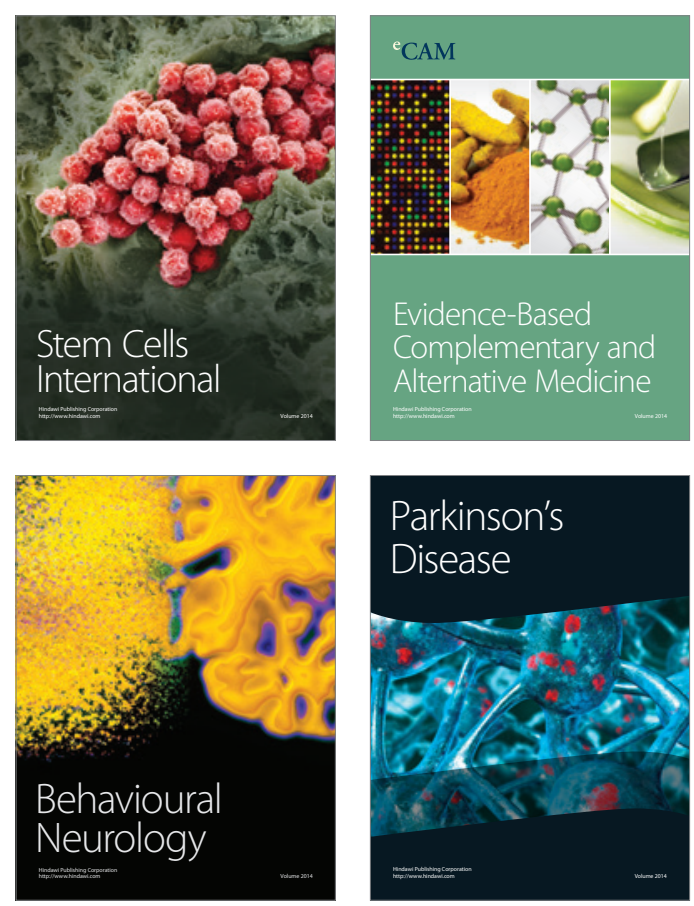

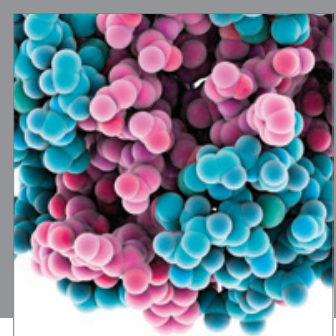

Journal of
Diabetes Research

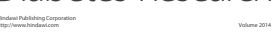

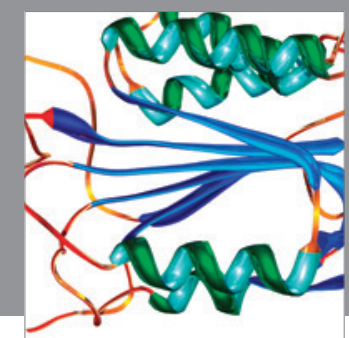

Disease Markers
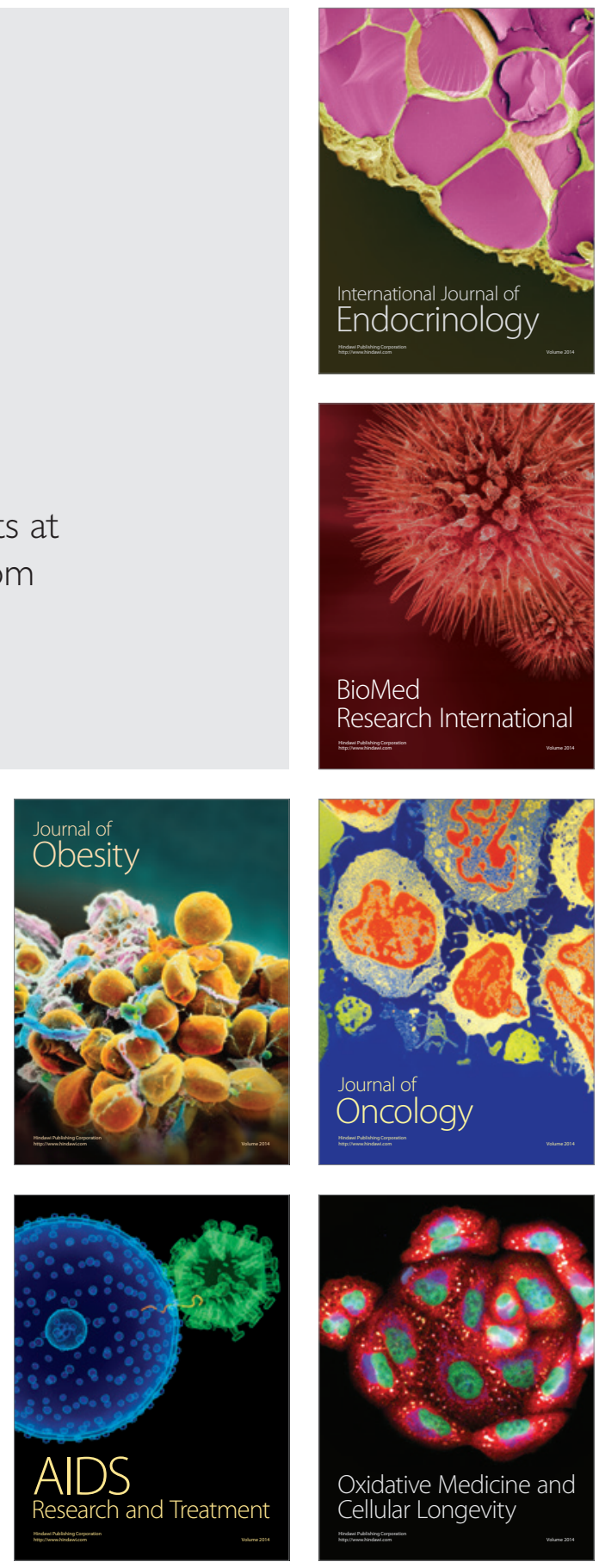